\title{
The impact of bevacizumab treatment on survival and quality of life in newly diagnosed glioblastoma patients
}

This article was published in the following Dove Press journal:

Cancer Management and Research

26 September 2014

Number of times this article has been viewed

\author{
Hans Skovgaard Poulsen ${ }^{1,2, *}$ \\ Thomas Urup ${ }^{1,2, *}$ \\ Signe Regner Michaelsen ${ }^{1,2}$ \\ Mikkel Staberg',2 \\ Mette Villingshøj ${ }^{1,2}$ \\ Ulrik Lassen ${ }^{1-3}$ \\ 'Department of Radiation Biology, \\ ${ }^{2}$ Department of Oncology, ${ }^{3}$ Phase I \\ Unit, The Finsencenter, Copenhagen \\ University Hospital, Copenhagen, \\ Denmark \\ *These authors contributed equally to \\ this work
}

Correspondence: Hans Skovgaard Poulsen Department of Radiation Biology, The Finsencenter, Section 632I, Copenhagen University Hospital, Blegdamsvej 9, 2100 Copenhagen, Denmark

Tel +453545 6303

Fax +4535456301

Email hans.skovgaard.poulsen@regionh.dk Homepage http://www.radiationbiology.dk

\begin{abstract}
Glioblastoma multiforme (GBM) remains one of the most devastating tumors, and patients have a median survival of 15 months despite aggressive local and systemic therapy, including maximal surgical resection, radiation therapy, and concomitant and adjuvant temozolomide. The purpose of antineoplastic treatment is therefore to prolong life, with a maintenance or improvement of quality of life. GBM is a highly vascular tumor and overexpresses the vascular endothelial growth factor A, which promotes angiogenesis. Preclinical data have suggested that anti-angiogenic treatment efficiently inhibits tumor growth. Bevacizumab is a humanized monoclonal antibody against vascular endothelial growth factor A, and treatment has shown impressive response rates in recurrent GBM. In addition, it has been shown that response is correlated to prolonged survival and improved quality of life. Several investigations in newly diagnosed GBM patients have been performed during recent years to test the hypothesis that newly diagnosed GBM patients should be treated with standard multimodality treatment, in combination with bevacizumab, in order to prolong life and maintain or improve quality of life. The results of these studies along with relevant preclinical data will be described, and pitfalls in clinical and paraclinical endpoints will be discussed.
\end{abstract}

Keywords: primary treatment, VEGF, quality of life, monoclonal antibody, patient survival, vascular tumor

\section{Introduction}

Glioblastoma multiforme (GBM) remains one of the most lethal tumors, and newly diagnosed patients have a median survival of 15 months despite aggressive therapy including maximal surgical resection, radiation therapy (RT), and concomitant and adjuvant temozolomide. ${ }^{1}$ GBM is characterized by excessive and aberrant angiogenesis, which is thought to be linked to expression of the prominent angiogenic promoter - the vascular endothelial growth factor A (VEGF). ${ }^{2,3}$ Bevacizumab (BVZ) (Avastin ${ }^{\circledR}$; Genentech, Inc., South San Francisco, CA, USA), a humanized monoclonal antibody targeting VEGF, has been suggested as a feasible anti-angiogenic drug. BVZ inhibits angiogenesis by clearing circulating VEGF and thereby preventing interaction of VEGF with its target receptors on the surface of endothelial cells. Consequently, BVZ does not have to cross the blood-brain barrier (BBB) in order to be active. Preclinical and clinical studies suggest that anti-angiogenic therapies such as BVZ, in part elicit their anti-tumor activity by transiently "normalizing" the tumor vasculature by inhibiting the formation of new blood vessels, thereby improving the efficacy of both chemotherapy and RT. ${ }^{4,5}$

Several phase II studies in GBM patients with recurrent disease have shown impressive response rates varying from $30 \%$ to $50 \%$, prolongation of life in responders, 
as well as improved quality of life (QOL). ${ }^{6-10}$ These studies have led to a number of investigations in newly diagnosed GBM patients, ${ }^{11-17}$ including well conducted prospective randomized phase III trials ${ }^{18-20}$ testing the hypothesis that GBM patients for first line therapy should be treated with standard multimodality treatment in combination with BVZ. In this paper we will discuss the results of these recent investigations of combining BVZ and standard treatment in newly diagnosed patients with primary GBM.

\section{Anti-angiogenic therapy rationale}

GBM tumor cells are known to produce VEGF primarily as a result of hypoxia, glucose deprivation, oxidative and mechanical stress, and mutations in both oncogenes and tumor suppressor genes. ${ }^{2}$ VEGF binds to its receptors on endothelial cells, resulting in new blood vessel formation, which facilitates tumor growth. Therefore, 4 decades ago, Judah Folkman hypothesized that anti-angiogenic therapy by vessel pruning would be an effective treatment strategy in cancer. ${ }^{21}$ Now, this hypothesis is widely accepted, and a variety of drugs targeting VEGF or its receptors have been shown to effectively prevent or reduce the growth of experimental mouse tumors and xenografts. ${ }^{22}$

However, the promising results from preclinical animal studies in GBM have not been translated into the clinic, suggesting that the mechanisms of angiogenesis are complicated and that escape mechanisms during single anti-angiogenic drug treatment with drugs such as BVZ occur. ${ }^{22-25}$ More recently, Rakesh $\mathrm{K}$ Jain formulated a new hypothesis which suggested that anti-angiogenic therapy elicits its anti-tumor activity by transiently normalizing the abnormal structure and function of tumor vasculature to make it more efficient for delivery of oxygen and chemotherapeutic agents. ${ }^{26}$ Evidence from several preclinical studies has confirmed that the temporary vascular normalization as a result of anti-angiogenic therapy, improves tumor blood perfusion, which consequently increases the delivery of chemotherapy and oxygen, and this potentially enhances the efficacy of both chemotherapy and RT. ${ }^{27-30}$ Recently, Batchelor et al provided clinical proof of concept that improved tumor blood perfusion, as a consequence of vascular normalization, was related to longer overall survival (OS) in newly diagnosed GBM patients treated with a combination of anti-angiogenic therapy (Cediranib) (Recentin ${ }^{\mathrm{TM}}$; AstraZeneca plc, London, UK) and standard treatment. ${ }^{5}$ These data remain to be validated, but strongly suggest that part of the beneficial response mechanisms of anti-angiogenic therapy in GBM patients is due to vascular normalization.
In addition to the paracrine stimulation of endothelial cells, recent data indicate that the GBM cells themselves also possess VEGF receptors and that autocrine stimulation of these receptors promotes tumor growth (Michaelsen et al, unpublished data, 2014). ${ }^{31}$ However, whether BVZ therapy has a directly disrupting effect on the autocrine growth stimulation of glioma cells in the perivascular niche, remains to be studied further.

\section{BVZ in newly diagnosed GBM Efficacy}

Over the years, seven phase II (including two randomized) ${ }^{11-17}$ and three phase III randomized studies ${ }^{18-20}$ with BVZ as part of the treatment of newly diagnosed GBM patients have been published. In three studies, BVZ was given as neoadjuvant treatment, ${ }^{11,12,14}$ while it was given as concomitant and adjuvant treatment in combination with RT in the remaining studies ${ }^{13,15-20}$ (Table 1). The response rates were comparable in both the neoadjuvant and adjuvant setting, and $23 \%$ to $38 \%$ responded to treatment, which is comparable to patients treated for recurrent disease. ${ }^{32}$

Progression free survival (PFS) at 6 months varied from $52 \%$ to $85 \%$, and median PFS from 7.3 to 14.2 months. Finally, median OS varied from 11.7 to 23 months. The studies ${ }^{11-20}$ varied in baseline characteristics such as patient age, performance status, degree of surgical resection, steroid use, and epigenetic silencing of $M G M T$ (O6-methylguanineDNA methyltransferase), which have been shown previously to have prognostic value, ${ }^{33,34}$ and this may explain some of the observed variations in response, PFS, and OS.

Among the published studies ${ }^{1-20}$ were two randomized Phase III studies, AVAGlio ${ }^{18}$ and RTOG $0825,{ }^{19}$ which compared standard treatment versus standard treatment plus BVZ. Both studies included newly diagnosed GBM patients in good performance status having MGMT methylated as well as non-methylated tumors. Known prognostic factors were comparable in the two studies except surgery, since more patients had debulking surgery in the RTOG 0825 study compared to the AVAGlio study. Both studies found significant increase in median PFS in the BVZ treatment arm compared to the placebo treatment arm (AVAGlio: 6.2 months to 10.6 months, $\sim 71 \%$ increase, and RTOG 0825: 7.3 months to 10.7 months, $\sim 47 \%$ increase). In contrast, no difference in OS was observed in either of the studies.

In both the AVAGlio ${ }^{18}$ and the RTOG $0825^{19}$ studies, the patients were allowed to cross over to BVZ-containing treatment at progression, and this occurred frequently. However, independently of whether BVZ was given as early treatment or as late treatment at recurrence, only a marginal, clinical 


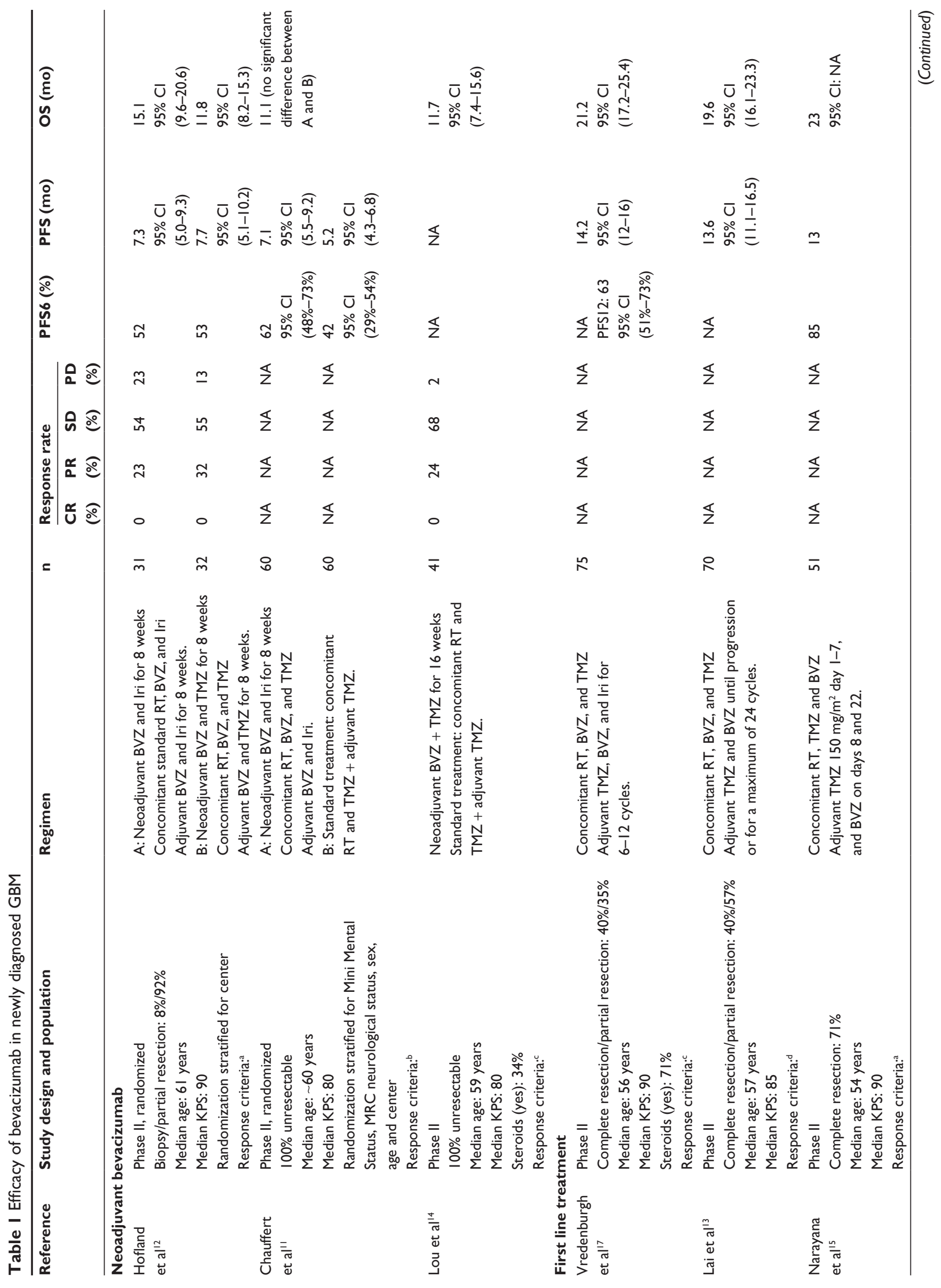




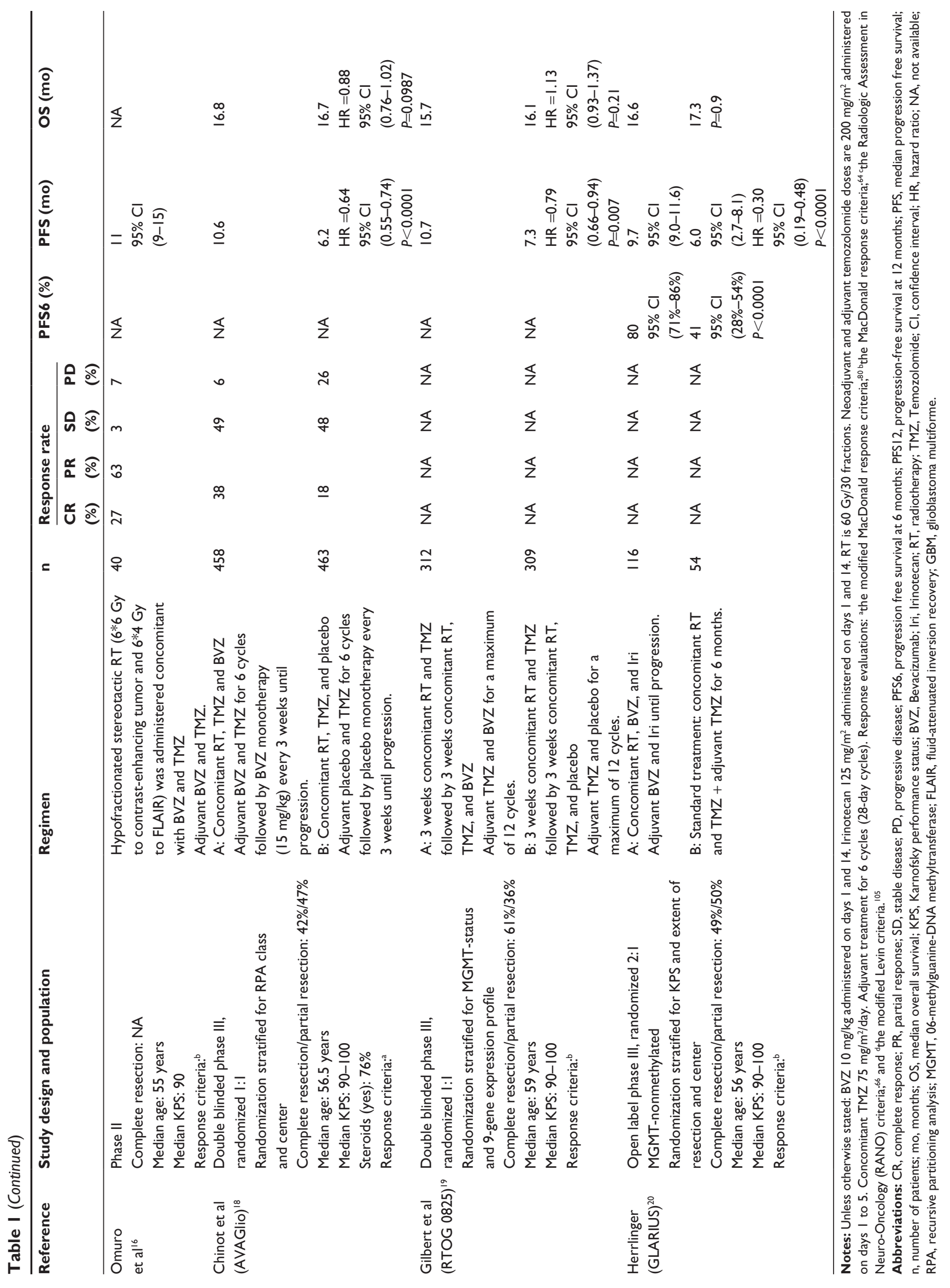


difference in median OS was seen as compared to the OS observed following standard treatment, as originally published by Stupp et al. ${ }^{1}$ This indicates that BVZ in general does not influence OS in patients with GBM. Whether subgroup analysis may define patients more sensitive to BVZ treatment still remains to be examined.

In contrast to comparable results for the effects of BVZ on PFS and OS, the AVAGlio and RTOG 0825 studies found contradicting results when evaluating QOL. The AVAGlio study $^{18}$ showed that increased PFS in the BVZ arm was accompanied by a better QOL, while the opposite if any change in QOL was found in the RTOG 0825 study. ${ }^{19}$

In addition to the above, a third Phase III randomized study, GLARIUS, has been published, in which standard treatment was compared to RT combined with concomitant and adjuvant BVZ, plus irinotecan. ${ }^{20}$ The study included non-methylated MGMT GBMs only, who are patients with supposedly worse prognoses as compared to patients with methylated MGMT. The data showed increased median OS in both arms as compared to published data from nonmethylated groups ${ }^{35}$ which indicates that some sort of selection other than MGMT methylation status might have occurred. Nevertheless, RT and concomitant and adjuvant BVZ plus irinotecan increased PFS, but not median OS, as compared to standard treatment. In addition, the QOL study did not show any difference. ${ }^{20}$ In conclusion, three well conducted, randomized Phase III studies ${ }^{18-20}$ could not demonstrate any survival benefit of adding BVZ to standard treatment in patients with newly diagnosed GBM.

\section{Safety of BVZ in the first line setting}

The Phase II studies ${ }^{11-17}$ and the three randomized studies $^{18-20}$ were comparable in terms of safety and toxicity according to the National Cancer Institute Common Terminology Criteria for Adverse Events (Table 2). In general, concomitant RT and TMZ with and without BVZ was well tolerated, with hematotoxicity being the most common toxicity in both treatment groups. ${ }^{11-20}$ The rates of serious adverse events were higher in the BVZ group than in the control group in the three randomized studies. ${ }^{18-20}$ Notably, it was observed in the randomized studies that grade $>3$ hypertension and thromboembolic events were significantly more frequent in patients treated with BVZ, as compared to standard treatment. ${ }^{18-20}$ In addition, in some studies, gastrointestinal perforation, cerebral bleeding, fatigue, wound healing complications, and proteinuria appeared more frequently in patients treated with BVZ, as compared to patients not receiving the drug. ${ }^{11,18-20}$

\section{Recurrence pattern}

The recurrence pattern is shown in Table 3. The data available are very heterogeneous and in general, the major studies ${ }^{18,36-38}$ do not uniformly support the assumption that BVZ treatment induces migratory growth at time of recurrence, resulting in more diffuse tumors. ${ }^{39,40}$

\section{Discussion}

Only a subset or approximately one third of patients with newly diagnosed or recurrent GBM respond to BVZ treatment, and some studies report a better QOL while others do not. ${ }^{9}{ }^{18-20}$ Several factors could be responsible for this, including molecular, cellular, and phenotypic resistance; problems in evaluating clinical and paraclinical response; and nonstandard procedure of reporting QOL data. Some important issues will be discussed in the following sections.

\section{Resistance to BVZ}

Multiple mechanisms of resistance to anti-angiogenic therapy have been described, and modes of resistance to antiangiogenic therapy can be classified into intrinsic resistance (where tumors fail to respond from the onset of treatment) and adaptive resistance (where tumors initially respond, and then progress whilst still on treatment). ${ }^{23}$ The molecular, cellular, and phenotypic bases of these two modes of resistance are still not well understood, and no molecular features have been identified which in clinical practice can predict which patient should be treated with anti-angiogenic therapy. ${ }^{41-43}$

Although increased blood flow might occur during a short normalization window, ${ }^{5}$ several studies have described hypoxia due to vascular pruning as being a central hallmark in resistance to long-term, anti-angiogenic therapy. $24,40,44,45$ Among other mechanisms, hypoxia induces upregulation of alternative angiogenic growth factors such as fibroblast growth factor 2, delta-like ligand 4, stromal cell-derived factor 1, platelet-derived growth factor alpha, angiopoietins, and placental growth factor. These and other angiogenic factors interact between tumor cells, endothelial cells, and stromal cells (eg, inflammatory cells and pericytes) in a complex network in order to adapt to anti-angiogenic therapy. Some factors, such as fibroblast growth factor 2, directly interact with receptors on endothelial cells to stimulate angiogenesis while others, such as stromal cell-derived factor 1, indirectly stimulate angiogenesis by recruiting proangiogenic, bone marrow-derived cells (BMDCs). ${ }^{23,24,46}$

Also, myeloid BMDCs may be involved in the resistant phenotype. Preclinical studies have shown an increase in the number of tumor-infiltrating, pro-angiogenic BMDCs 
Table 2 Toxicity of bevacizumab in newly diagnosed GBM

\begin{tabular}{|c|c|c|c|c|}
\hline \multirow[t]{2}{*}{ Reference } & \multirow[t]{2}{*}{ Regimen } & \multirow[t]{2}{*}{ Toxicity (NCl-CTCAE) } & \multicolumn{2}{|l|}{ Grade $\geq 3, \%$} \\
\hline & & & Treatment arm A & Treatment arm B \\
\hline \multicolumn{5}{|c|}{ Neoadjuvant BVZ } \\
\hline Hofland & A: Neoadjuvant BVZ and & Hematotoxicity & & \\
\hline \multirow[t]{16}{*}{ et $\mathrm{al}^{12}$} & Iri for 8 weeks & Leukopenia & 3.2 & 9.4 \\
\hline & Concomitant standard RT, & Lymphopenia & 6.5 & 6.3 \\
\hline & BVZ, and Iri & Thrombocytopenia & 0.0 & 9.4 \\
\hline & Adjuvant BVZ and Iri for & Bleeding & & \\
\hline & 8 weeks. & Cerebral hemorrhage & 0.0 & 0.0 \\
\hline & B: Neoadjuvant BVZ and & Mucocutaneous bleeding & NA & NA \\
\hline & TMZ for 8 weeks & Other & NA & NA \\
\hline & Concomitant RT, BVZ, and TMZ & Wound dehiscence & 0.0 & 0.0 \\
\hline & Adjuvant $B V Z$ and $T M Z$ for & Arterial thromboembolic events & 0.0 & 0.0 \\
\hline & 8 weeks. & Venous thromboembolic events (DVT/PE) & 3.2 & 0.0 \\
\hline & & Hypertension & 0.0 & 9.4 \\
\hline & & Proteinuria & NA & NA \\
\hline & & GI perforation (including GI fistula/abscess) & 0.0 & 0.0 \\
\hline & & Abscesses and fistulae & 0.0 & 0.0 \\
\hline & & Congestive heart failure & 0.0 & 0.0 \\
\hline & & $\begin{array}{l}\text { Posterior reversible encephalopathy } \\
\text { syndrome }\end{array}$ & 0.0 & 0.0 \\
\hline Chauffert & A: Neoadjuvant BVZ and & Hematotoxicity & & \\
\hline \multirow[t]{16}{*}{ et $\mathrm{al}^{\prime \prime}$} & Iri for 8 weeks & Neutropenia & 7.0 & 8.9 \\
\hline & Concomitant RT, BVZ, and TMZ & Lymphopenia & 12.3 & 12.5 \\
\hline & Adjuvant BVZ and Iri. & Thrombocytopenia & 3.5 & 14.2 \\
\hline & B: Standard treatment: & Bleeding & & \\
\hline & concomitant RT and & Cerebral hemorrhage & 5.3 ( 3 patients grade 5$)$ & I.8 (I patient grade 5$)$ \\
\hline & $T M Z$ + adjuvant TMZ. & Mucocutaneous bleeding & NA & NA \\
\hline & 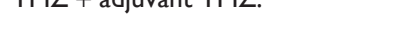 & Other & NA & NA \\
\hline & & Wound dehiscence & NA & NA \\
\hline & & Arterial thromboembolic events & 1.8 & 1.8 \\
\hline & & Venous thromboembolic events (DVT/PE) & 8.8 & 0.0 \\
\hline & & Hypertension & 0.0 & 0.0 \\
\hline & & Proteinuria & NA & NA \\
\hline & & GI perforation/infection & 5.3 (I patient grade 5) & 3.6 (I patient grade 5$)$ \\
\hline & & Abscesses and fistulae & NA & NA \\
\hline & & Congestive heart failure & NA & NA \\
\hline & & $\begin{array}{l}\text { Posterior reversible encephalopathy } \\
\text { syndrome }\end{array}$ & NA & NA \\
\hline \multirow[t]{16}{*}{ Lou et al ${ }^{14}$} & Neoadjuvant BVZ + TMZ & Hematotoxicity & & \\
\hline & for 16 weeks. & Neutropenia & 4.9 & \\
\hline & Standard treatment: & Thrombocytopenia & 7.3 & \\
\hline & Concomitant RT and & Bleeding & & \\
\hline & TMZ + adjuvant TMZ. & Cerebral hemorrhage & 0.0 & \\
\hline & & Mucocutaneous bleeding & NA & \\
\hline & & Other & NA & \\
\hline & & Wound-healing complications & 2.4 & \\
\hline & & Arterial thromboembolic events & 2.4 (I patient grade 5) & \\
\hline & & Venous thromboembolic events (DVT/PE) & 9.8 & \\
\hline & & Hypertension & NA & \\
\hline & & Proteinuria & NA & \\
\hline & & GI perforation & 2.4 & \\
\hline & & Abscesses and fistulae & NA & \\
\hline & & Congestive heart failure & 2.4 & \\
\hline & & $\begin{array}{l}\text { Posterior reversible encephalopathy } \\
\text { syndrome }\end{array}$ & NA & \\
\hline \multicolumn{5}{|c|}{ First line treatment } \\
\hline Vredenburgh & Concomitant RT, BVZ, and TMZ & I.3\% (I patient) grade 5 neutropenic sepsis; & & \\
\hline et $\mathrm{al}^{17}$ & Adjuvant TMZ, BVZ, and Iri for & I.3\% (I patient) grade 5 PE; & & \\
\hline & 6-12 cycles. & I.3\% (I patient) Gl perforation. & & \\
\hline
\end{tabular}


Table 2 (Continued)

\begin{tabular}{|c|c|c|c|c|}
\hline \multirow[t]{2}{*}{ Reference } & \multirow[t]{2}{*}{ Regimen } & \multirow[t]{2}{*}{ Toxicity } & \multicolumn{2}{|l|}{ Grade $\geq 3, \%$} \\
\hline & & & Treatment arm A & Treatment arm B \\
\hline \multirow[t]{14}{*}{ Lai et $\mathrm{al}^{13}$} & Concomitant RT, BVZ, and TMZ & Hematotoxicity & NA & \\
\hline & Adjuvant TMZ and BVZ until & Bleeding & & \\
\hline & progression or for a maximum & Cerebral hemorrhage & 2.9 & \\
\hline & of 24 cycles. & GI bleeding & 2.9 & \\
\hline & & Other & 1.4 & \\
\hline & & Wound-healing complications & NA & \\
\hline & & Arterial thromboembolic events & NA & \\
\hline & & Venous thromboembolic events (DVT/PE) & 18.6 & \\
\hline & & Hypertension & $1 \mathrm{I} .4$ & \\
\hline & & Proteinuria & 11.4 & \\
\hline & & GI perforation & 2.9 & \\
\hline & & Abscesses and fistulae & NA & \\
\hline & & Congestive heart failure & NA & \\
\hline & & $\begin{array}{l}\text { Posterior reversible encephalopathy } \\
\text { syndrome }\end{array}$ & NA & \\
\hline \multirow{14}{*}{$\begin{array}{l}\text { Narayana } \\
\text { et } \text { al }^{15}\end{array}$} & Concomitant RT, TMZ, and BVZ & Hematotoxicity & NA & \\
\hline & Adjuvant TMZ $150 \mathrm{mg} / \mathrm{m}^{2}$ & Bleeding & & \\
\hline & days $\mathrm{I}-7$, and $\mathrm{BVZ}$ on & Cerebral hemorrhage & 0.0 & \\
\hline & days 8 and 22 . & Mucocutaneous bleeding & 0.0 & \\
\hline & & Other & 0.0 & \\
\hline & & Wound-healing complications & NA & \\
\hline & & Arterial thromboembolic events & NA & \\
\hline & & Venous thromboembolic events (DVT/PE) & 5.9 & \\
\hline & & Hypertension & NA & \\
\hline & & Proteinuria & NA & \\
\hline & & GI perforation (including GI fistula/abscess) & NA & \\
\hline & & Abscesses and fistulae & NA & \\
\hline & & Congestive heart failure & NA & \\
\hline & & $\begin{array}{l}\text { Posterior reversible encephalopathy } \\
\text { syndrome }\end{array}$ & NA & \\
\hline Omuro & Hypofractionated stereotactic & Hematotoxicity & NA & \\
\hline \multirow[t]{13}{*}{ et $\mathrm{al}^{16}$} & RT (6*6 Gy to contrast- & Bleeding & NA & \\
\hline & enhancing tumor and $6 * 4 \mathrm{~Gy}$ & Cerebral hemorrhage & & \\
\hline & to FLAIR) was administered & GI bleeding & & \\
\hline & concomitant with BVZ and TMZ & Other & & \\
\hline & Adjuvant BVZ and TMZ. & Wound-healing complications & NA & \\
\hline & & Arterial thromboembolic events & NA & \\
\hline & & $\mathrm{PE}$ & 5.0 & \\
\hline & & Hypertension & NA & \\
\hline & & Proteinuria & NA & \\
\hline & & Gl perforation & NA & \\
\hline & & Abscesses and fistulae & NA & \\
\hline & & Congestive heart failure & NA & \\
\hline & & $\begin{array}{l}\text { Posterior reversible encephalopathy } \\
\text { syndrome }\end{array}$ & NA & \\
\hline \multirow{13}{*}{$\begin{array}{l}\text { Chinot et al } \\
\text { (AVAGlio) }^{18}\end{array}$} & A: Concomitant RT, TMZ, & Hematotoxicity & & \\
\hline & and $B V Z$ & Thrombocytopenia & 15.0 & 9.8 \\
\hline & Adjuvant BVZ and TMZ for & Bleeding & & \\
\hline & 6 cycles followed by BVZ & Cerebral hemorrhage & 2.0 & 0.9 \\
\hline & monotherapy $(15 \mathrm{mg} / \mathrm{kg})$ every & Other, including mucocutaneous bleeding & 1.3 & 0.9 \\
\hline & 3 weeks until progression. & Wound-healing complications & 3.3 & 1.6 \\
\hline & B: Concomitant RT, TMZ, & Arterial thromboembolic events & 5.0 & 1.3 \\
\hline & and placebo & Venous thromboembolic events (DVT/PE) & 7.6 & 8.0 \\
\hline & Adjuvant placebo and TMZ for & Hypertension & 11.3 & 2.2 \\
\hline & 6 cycles followed by placebo & Proteinuria & 5.4 & 0.0 \\
\hline & monotherapy every 3 weeks & GI perforation (including GI fistula/abscess) & I.I & 0.2 \\
\hline & monotherapy every 3 weeks & Abscesses and fistulae & 0.4 & 0.7 \\
\hline & until progression. & Congestive heart failure & 0.4 & 0.0 \\
\hline
\end{tabular}


Table 2 (Continued)

\begin{tabular}{|c|c|c|c|c|}
\hline \multirow[t]{2}{*}{ Reference } & \multirow[t]{2}{*}{ Regimen } & \multirow[t]{2}{*}{ Toxicity } & \multicolumn{2}{|l|}{ Grade $\geq 3, \%$} \\
\hline & & & Treatment arm A & Treatment arm B \\
\hline & & $\begin{array}{l}\text { Posterior reversible encephalopathy } \\
\text { syndrome }\end{array}$ & 0.0 & 0.0 \\
\hline & & Fatigue & 7.4 & 4.7 \\
\hline \multirow{19}{*}{$\begin{array}{l}\text { Gilbert et al } \\
\text { (RTOG 0825) }^{19}\end{array}$} & A: 3 weeks' concomitant RT & Hematotoxicity & & \\
\hline & and TMZ followed by 3 weeks' & Anemia & 2.6 & 1.6 \\
\hline & concomitant RT, TMZ, and BVZ & Leukopenia & 13.8 & 8.3 \\
\hline & Adjuvant $\mathrm{TMZ}$ and $\mathrm{BVZ}$ for a & Neutropenia & 17.2 & 9.3 \\
\hline & maximum of 12 cycles. & Lymphopenia & 23.7 & 22.3 \\
\hline & B: 3 weeks' concomitant RT & Thrombocytopenia & 21.4 & 19.3 \\
\hline & and TMZ followed by 3 weeks' & Bleeding & I.5 (I patient grade 5) & 1.3 \\
\hline & concomitant RT, TMZ, and & Cerebral hemorrhage & NA & NA \\
\hline & placebo & Mucocutaneous bleeding & NA & NA \\
\hline & Adjuvant TMZ and placebo & Other & NA & NA \\
\hline & for a maximum of 12 cycles. & Wound-healing complications & 2.5 & I.I \\
\hline & & Thromboembolic events (arterial/venous) & II.9 (I patient grade 5) & 8.4 \\
\hline & & Hypertension & 5.5 & 1.2 \\
\hline & & Proteinuria & NA & NA \\
\hline & & Gl perforation & 1.5 & 0.7 \\
\hline & & Abscesses and fistulae & NA & NA \\
\hline & & Congestive heart failure & NA & NA \\
\hline & & $\begin{array}{l}\text { Posterior reversible encephalopathy } \\
\text { syndrome }\end{array}$ & NA & NA \\
\hline & & Fatigue & 15.4 & 11.7 \\
\hline \multirow{15}{*}{$\begin{array}{l}\text { Herrlinger } \\
\text { (GLARIUS) }^{20}\end{array}$} & A: Concomitant RT, BVZ, and Iri & Hematotoxicity & 1.7 & 14.6 \\
\hline & Adjuvant BVZ and Iri until & Bleeding & & \\
\hline & progression. & Cerebral hemorrhage & 0.8 & 0.0 \\
\hline & B: Standard treatment: & Subdural hematoma & 0.0 & 3.6 \\
\hline & concomitant RT and TMZ + & Mucocutaneous bleeding & NA & NA \\
\hline & adjuvant TMZ for 6 months. & Other & NA & NA \\
\hline & & Wound-healing complications & 0.8 & 0.0 \\
\hline & & Arterial thromboembolic events & NA & NA \\
\hline & & Venous thromboembolic events (DVT/PE) & 5.9 & 1.8 \\
\hline & & Hypertension & 8.4 & 1.8 \\
\hline & & Proteinuria & 2.7 & 0.0 \\
\hline & & Gl perforation (including GI fistula/abscess) & 0.8 & 0.0 \\
\hline & & Abscesses and fistulae & NA & NA \\
\hline & & Congestive heart failure & NA & NA \\
\hline & & $\begin{array}{l}\text { Posterior reversible encephalopathy } \\
\text { syndrome }\end{array}$ & 0.8 & 0.0 \\
\hline
\end{tabular}

Notes: Other bleeding refers to bleeding from other organs.

Abbreviations: BVZ, Bevacizumab; Iri, Irinotecan; RT, radiotherapy; TMZ, Temozolomide; DVT, deep vein thrombosis; PE, pulmonary embolism; GI, gastrointestinal; NA, not available; FLAIR, fluid-attenuated inversion recovery; GBM, glioblastoma multiforme.

during tumor progression while on anti-angiogenic therapy. ${ }^{23,25,47}$ Myeloid BMDCs consist of a variety of cell subpopulations including tumor-associated macrophages, which appear to constitute the largest subpopulation in GBM patient tumors after progression on anti-angiogenic therapy. ${ }^{47}$ Tumor-associated macrophages are believed to induce resistance by the release of potent pro-angiogenic factors, a variety of cytokines, growth factors, and vascularmodulating enzymes ${ }^{48}$ Similarly, other subpopulations of BMDCs have been described as being involved in mechanisms of resistance to anti-angiogenic therapy in GBM. ${ }^{49-51}$ A common feature of most studies describing BMDCs in GBM is the use of xenograft models, which are characterized by the lack of a normal immune system, ${ }^{25,50-52}$ and this may have influenced the observations of these studies. Future studies on BMDCs and other immune cells from patient GBM tissue or preclinical models other than the xenograft model might provide new knowledge of the immune system's role in resistance to anti-angiogenic therapy in GBM patients. 
Table 3 Patterns of recurrence in bevacizumab treated GBM patients

\begin{tabular}{|c|c|c|c|c|c|}
\hline $\begin{array}{l}\text { Reference and } \\
\text { evaluation criteria }\end{array}$ & Regimen & $\mathbf{n}$ & $\begin{array}{l}\text { Pattern at } \\
\text { baseline }(n)\end{array}$ & $\begin{array}{l}\text { Local or non-diffuse } \\
\text { recurrences, \% (n) }\end{array}$ & $\begin{array}{l}\text { Diffuse or multifocal } \\
\text { recurrences, \% (n) }\end{array}$ \\
\hline \multicolumn{6}{|l|}{ First line treatment } \\
\hline Narayana et al ${ }^{15}$ & Concomitant RT, TMZ, and BVZ & 35 & NA (35) & $43(15)$ & $57(20)$ \\
\hline Evaluation criteria: ${ }^{a}$ & $\begin{array}{l}\text { Adjuvant TMZ } 150 \mathrm{mg} / \mathrm{m}^{2} \text { days } \mathrm{I}-7 \text {, } \\
\text { and BVZ on days } 8 \text { and } 22 \text {. }\end{array}$ & & & & \\
\hline Chinot et al & A: Standard treatment + & 294 & Local (2।8) & $89(194)$ & II (24) \\
\hline (AVAGlio) $^{18}$ & concomitant, adjuvant, & & Multifocal (75) & $12(9)$ & $88(66)$ \\
\hline \multirow[t]{6}{*}{ Evaluation criteria: ${ }^{a}$} & and maintenance BVZ. & & Non-diffuse (89) & $75(67)$ & $25(22)$ \\
\hline & & & Diffuse (205) & $2(4)$ & $98(201)$ \\
\hline & B: Standard treatment + & 314 & Local (24I) & $89(2 \mid 4)$ & II (27) \\
\hline & concomitant, adjuvant, & & Multifocal (73) & $8(6)$ & $92(67)$ \\
\hline & and maintenance placebo. & & Non-diffuse (I27) & $77(98)$ & $23(29)$ \\
\hline & & & Diffuse (187) & $2(3)$ & $98(184)$ \\
\hline \multicolumn{6}{|c|}{ Second or third line treatment } \\
\hline Norden et $\mathrm{al}^{101}$ & BVZ in combination. & 26 & NA (26) & $62(16)$ & $31(8)$ \\
\hline \multicolumn{6}{|l|}{ Evaluation criteria: ${ }^{b}$} \\
\hline Iwamoto et al $\left.\right|^{106}$ & BVZ alone or in combination. & 37 & NA (37) & $46(17)$ & $54(19)$ \\
\hline \multicolumn{6}{|l|}{ Evaluation criteria:b } \\
\hline Narayana et al $^{107}$ & BVZ in combination with Iri or & 50 & NA (50) & $70(35)$ & $30(15)$ \\
\hline Evaluation criteria:b & carboplatin. & & & & \\
\hline Pope et $\mathrm{al}^{38}$ & A: BVZ alone. & 124 & Local (88) & $63(55)$ & $37(33)$ \\
\hline \multirow[t]{2}{*}{ Evaluation criteria: ${ }^{c}$} & B: BVZ + Iri. & & Multifocal or distant (10) & $0(0)$ & $100(10)$ \\
\hline & & & Diffuse (26) & $0(0)$ & $100(26)$ \\
\hline Chamberlain et $\mathrm{al}^{37}$ & BVZ alone. & 80 & Local (65) & $88(57)$ & $12(8)$ \\
\hline \multicolumn{6}{|l|}{ 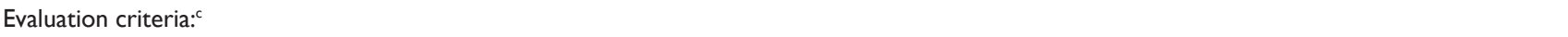 } \\
\hline Wick et al ${ }^{108}$ & BVZ alone or in combination & 44 & NA (44) & $77(34)$ & $23(10)$ \\
\hline Evaluation criteria: ${ }^{d}$ & with multiple agents. & & & & \\
\hline Bloch et $\mathrm{al}^{36}$ & BVZ alone or in combination. & 71 & Local (7I) & $83(59)$ & $17(12)$ \\
\hline \multicolumn{6}{|l|}{ Evaluation criteria: ${ }^{d}$} \\
\hline Soffietti et al ${ }^{109}$ & BVZ + Fotemustine. & 50 & Local (42) & $76(32)$ & $24(10)$ \\
\hline Evaluation criteria: ${ }^{d}$ & & & Multifocal (8) & $0(0)$ & $100(8)$ \\
\hline Desjardins et al ${ }^{110}$ & $\mathrm{BVZ}+\mathrm{TMZ}$ & 21 & NA (2I) & $52(\mathrm{II})$ & $48(10)$ \\
\hline
\end{tabular}

Notes: Tumor progression patterns at baseline and time of on-study progression were evaluated according to different criteria: athe modified MacDonald Response Criteria; ${ }^{80}$ b the MacDonald Response Criteria; ${ }^{64}$ the Pope Criteria; ${ }^{38}$ and ${ }^{d}$ the Radiologic Assessment in Neuro-Oncology (RANO) criteria. ${ }^{66}$

Abbreviations: BVZ, Bevacizumab; Iri, Irinotecan; RT, radiotherapy; TMZ, Temozolomide; NA, not available; GBM, glioblastoma multiforme; n, number of patients in the whole table.

Several studies have reported tumor invasion as being an important resistance mechanism to BVZ. 24,40,44,45 Among the theories for development of an invasive BVZ-resistant tumor phenotype is the involvement of the tyrosine kinase c-mesenchymal-epithelial transition factor (c-Met), which in both preclinical animal studies and in patient GBM tumors has been shown to be upregulated during progression on antiangiogenic therapy. ${ }^{25,53,54} \mathrm{c}$-Met seems to be involved in resistance to anti-angiogenic therapy by promoting tumor invasion and importantly, this resistance mechanism was blocked by inhibiting c-Met in combination with anti-angiogenic therapy. ${ }^{53}$ Although the recurrence patterns from the clinical studies described in Table 3 do not support increased migratory growth during anti-angiogenic therapy, ${ }^{18,36-38}$ these findings suggest that the combination of anti-angiogenic therapy and a c-Met inhibitor may produce a more efficacious therapeutic effect in GBM.
Moreover, the expression of VEGF receptor 2 on GBM cells has been suggested as a resistance mechanism to BVZ. ${ }^{31}$ In some GBM cells, the receptor is believed to be activated in an autocrine manner by VEGF, and has been linked to promotion of cell proliferation and tumor growth, in addition to the formation of vessel-like structures from the tumor cells themselves, thereby making the tumors independent of the normal endothelial cell-derived vasculature. ${ }^{31,55,56}$ As BVZ can only cross the BBB in areas where the BBB is disrupted, and BVZ has to diffuse against a high intratumoral pressure gradient, autocrine VEGF stimulation will probably not be targeted. ${ }^{57}$ In addition, new data from our laboratory suggest that the receptors in GBM are not solely dependent on VEGF, but are additionally activated by the growth factor vascular endothelial growth factor $\mathrm{C}$ (Michaelsen et al, unpublished data, 2014), which also could explain resistance to BVZ. 
Additionally, recent data presented at the American Society of Clinical Oncology (ASCO) indicate that different molecular subtypes of GBM may represent tumor phenotypes with different resistance profiles to BVZ. This study performed subgroup analysis on GBM tissue taken from the AVAGlio study ${ }^{58} \mathrm{~A}$ total of 99 patients (56 receiving placebo treatment and $43 \mathrm{BVZ}$ treatment) were classified into four subtypes by gene expression analysis: proneural, mesenchymal, proliferative, and unclassified. ${ }^{59,60}$ In addition, IDHI mutation status analysis was performed. It was demonstrated that patients with proneural tumors without $I D H 1$ mutation had a significantly longer median OS in the BVZ treatment group compared to the control treatment group (17.1 and 12.1 months, respectively; hazard ratio $0.63,95 \%$ confidence interval: $0.4-0.99 ; P=0.043)$. Although this potential predictor needs validation in an independent dataset, it could potentially be used for patient and therapy stratification in the future, and it provides more information on BVZ resistance and mode of action.

In conclusion, many mechanisms have been suggested as responsible for BVZ resistance. However, no clear molecular or adaptive data definitively explain why only some GBM patients respond to BVZ.

\section{Dosing and scheduling}

Different dosing and scheduling strategies of BVZ were used in the three randomized phase III trials (Table 1). In all three studies, BVZ was administered concomitant and adjuvant at a dose of $10 \mathrm{mg} / \mathrm{kg}$ every 2 weeks, starting at week 4 of RT in the RTOG $0825^{19}$ and day 1 of RT in the AVAGlio ${ }^{18}$ and GLARIUS $^{20}$ trials. The adjuvant treatment phase in the three studies varied in length, dosing, and scheduling. The dosing and scheduling were based on previously reported trials on recurrent GBM and other non-GBM malignancies..$^{32,61}$ Although BVZ is most often used at a dose of $10 \mathrm{mg} / \mathrm{kg}$ administered every 2 weeks in recurrent GBM until toxicity or progression occurs, its optimal dose has not been established yet. A meta-analysis of BVZ for recurrent GBM in 548 patients from 15 phase II studies reported no difference in efficacy between BVZ at $5 \mathrm{mg} / \mathrm{kg}$ and higher doses $(10 \mathrm{mg} / \mathrm{kg}$ every 2 weeks or $15 \mathrm{mg} / \mathrm{kg}$ every 3 weeks), and this inconsistent dose-response relationship has also been reported in other non-GBM malignancies. ${ }^{61}$ Nevertheless, the efficacy and toxicity of these different doses warrants further investigation in prospective clinical trials.

The GLARIUS ${ }^{20}$ and the AVAGlio ${ }^{18}$ trials continued treatment until progression. Recent retrospective data on recurrent GBM have shown that BVZ discontinuation unrelated to disease progression does not appear to cause rebound recurrence or shorten PFS in patients who benefit from BVZ. ${ }^{62}$ However, the optimal duration of BVZ treatment and the impact of discontinuation requires prospective evaluation in clinical trials.

\section{Safety}

Regardless of the potential benefits of BVZ in combination with standard therapy, BVZ is associated with higher risk of several potential toxicities when combined with standard radiotherapy. The most frequent toxicity was hypertension, and BVZ was also associated with an increased risk of arterial and venous thromboembolic events. ${ }^{18-20}$ Other observed BVZ toxicities were gastrointestinal perforation, cerebral bleeding, fatigue, wound healing complications, and proteinuria. ${ }^{11,18-20}$ Evaluation for these toxicities is important in BVZ-treated patients, because early intervention may decrease morbidity and mortality risk if this treatment moves into first line treatment in the future. Additionally, treatment with BVZ can significantly alter a patient's treatment planning, as it can require treatment cessation to avoid exacerbation of an adverse event. However, the data on the optimal toxicity management guidelines are currently limited, and are based on the experiences in recurrent GBM and a variety of nonGBM cancers. ${ }^{63}$

\section{Clinical endpoints of GBM treatment}

When assessing clinical efficacy, different endpoints are used in various malignant diseases. Interpreting endpoints in GBM presents several hurdles, especially when treating with anti-angiogenic drugs. These problems are discussed in the following section.

\section{Response evaluation}

Tumor response is normally evaluated by the MacDonald Criteria and/or the Radiologic Assessment in NeuroOncology (RANO) criteria, which are based on a combination of tumor measurements, or estimates based on contrastand non-enhancing tumor images and utilizing magnetic resonance imaging (MRI) scan techniques, including MRI T2-weighted and fluid-attenuated inversion recovery image sequences. In addition, corticosteroid dose and neurological status are evaluated..$^{64-66}$

Response evaluation has some inherent difficulties. Tumor enhancement can be non-specific, as it also partly represents peritumoral edema due to the leakiness of tumor vessels. Moreover, enhancement can be influenced by changes in corticosteroid dose and radiologic technique. In addition, 
increased enhancement can be caused by other processes that are not related to tumor progression such as treatmentrelated inflammation, seizure activity, post-surgical changes, ischemia, and radiation effects. ${ }^{67-70}$

Pseudo-progression is an increase in contrast enhancement unrelated to tumor progression. Pseudo-progression is seen in $20 \%-30 \%$ of patients receiving RT and temozolomide, is a result of increased permeability of vasculature after $\mathrm{RT}$, and can be accompanied by progressive neurological symptoms. ${ }^{71-74}$

Other limitations include difficulty in measuring irregular-shaped tumors, inter-observer variability, lack of assessment of the non-enhancing tumor component, and limitations when assessing multifocal tumors and walls of cystic or surgical cavities. ${ }^{75-77}$

Anti-angiogenic treatment raises new challenges, as MRI scans can sometimes show signs of response to such treatment due to normalization of tumor vasculature, not necessarily antitumor activity, and therefore represent a so-called pseudo-response. As a consequence, it is postulated that anti-angiogenic treatment might control contrast-enhancing tumors more effectively than non-enhancing tumors, which can cause problems when interpreting MRI scans. ${ }^{24} \mathrm{As}$ anti-angiogenic treatment seems to control tumor enhancement as early as $1-2$ days after initiation of treatment, 32,78 non-enhancing tumors may continue to grow and therefore, measuring only the enhancing lesion fails to correctly estimate tumor growth. ${ }^{75,76,79}$

Difficulties assessing non-enhancing tumors using MRI can arise from the fact that increases in $\mathrm{T} 2$ and fluid-attenuated inversion recovery signal can arise from post-irradiation damage, decreased glucocorticoid dosage, postoperative changes, seizure activity, demyelinization, and ischemic injury, and can mistakenly be interpreted as tumor progression. ${ }^{9}$

In recognition of the potential challenges with response assessment, the AVAGlio study ${ }^{18}$ used the modified response criteria, ${ }^{80}$ while both the RTOG $0825^{19}$ and the GLARIUS ${ }^{20}$ studies used the MacDonald Criteria. ${ }^{64}$ In these studies, there seems to be a strong concordance in determining response and progression by different "standardized criteria" ${ }^{81}$ but it cannot be excluded that variation in the estimate of PFS in the three randomized studies might be due to differences in interpretation of response.

Recently, baseline ${ }^{18} \mathrm{~F}$-fluoro-D-glucose (FDG)-PET (positron emission tomography) imaging has been suggested as a feasible biomarker in recurrent GBM patients for predicting tumor control and survival following anti-angiogenic therapy with BVZ. ${ }^{82}$ However, due to the high rate of glucose metabolism in normal brain tissue and in inflammatory cells, FDG has shown diagnostic limitations when used for brain tumor imaging. ${ }^{83}$ In contrast, radiolabeled amino acids have a relatively low uptake in normal brain tissue and usually accumulate intensely in tumor cells. Preclinical and clinical studies have shown that ${ }^{18} \mathrm{~F}$ amino acid and nucleic analog PET tracers, eg, $\mathrm{O}-\left(2-{ }^{18} \mathrm{~F}\right.$-fluoroethyl)-L-tyrosine and $\left[{ }^{18} \mathrm{~F}\right]$-fluoro-L-thymidine, are superior to the FDG-PET in predicting treatment efficacy, and that predictability is enhanced by a combination of both PET and MRI. ${ }^{84-86}$ Although these techniques still need to be validated, non-invasive PET tracers, in addition to MRI, may add information in response assessment, which could be useful for clinical decision making, eg, discontinuation of BVZ.

\section{PFS and OS}

When assessing the efficacy of drugs in clinical trials, PFS and OS have been the most commonly used primary endpoints. ${ }^{1,18-20,32} \mathrm{OS}$ is a straightforward endpoint that apparently offers a simple interpretation. ${ }^{87}$ However, OS is likely to be influenced by the subsequent anticancer treatments the patients receive after going off-study for any reason (eg, due to disease progression or intolerable toxicities).

Treatment with BVZ in patients with GBM seems to increase median PFS, but not OS. However, evaluating PFS depends on accurate and objective means to detect progression. Further, it is influenced by pseudo-progression and pseudo-response (see the "Response evaluation" section), especially in patients receiving temozolomide in combination with radiation and anti-angiogenic treatment, and these problems may lead to inaccurate estimation of PFS. ${ }^{88}$

\section{QOL}

Maintenance or increase of QOL is an important endpoint in the treatment of GBM. GBM is accompanied by neurological and cognitive impairments in almost all patients. ${ }^{89}$ These impairments are related to the tumor and its position in the central nervous system, tumor-related epilepsy, and treatment related factors. ${ }^{9,89,91}$ When treating GBM patients with targeted therapies such as anti-angiogenic agents, QOL should be taken into consideration, since treatment could delay deterioration of neurological and cognitive functions and thereby improve QOL. Although still controversial, especially in newly diagnosed GBMs, some evidence suggest that BVZ produces an improvement or preservation of neurocognitive function. ${ }^{8}$

Headache, nausea, and vomiting are frequent symptoms seen in patients with GBM, which are due to increased intracranial pressure caused by peritumoral edema. Administering corticosteroids can diminish peritumoral edema, thereby 
alleviating the symptoms associated with increased intracranial pressure. On the other hand, corticosteroids may induce negative effects on neurocognitive function and/or QOL, ${ }^{92-94}$ and it has been documented that corticosteroid use in primary brain tumors and metastases can lead to increases in blood glucose levels, peripheral edema, psychiatric disorders, and Cushing's syndrome. ${ }^{95,96}$ However, the reduced intracranial pressure associated with corticosteroid treatment improves neurocognitive functions and QOL, despite other corticosteroid-induced adverse effects.

Studies, including the AVAGlio study, have shown that BVZ has a steroid-sparing effect, which may be a consequence of improved tumor control as well as alleviation of vasogenic brain edema. This would be expected to positively impact QOL due to lower corticosteroid dose and, therefore, less corticosteroid-related toxicity., ${ }^{9,1863,81-85}$ Moreover, the steroid-sparing effect of BVZ is associated with clinical response and improved neurological symptoms in high-grade glioma, or GBM. .4,86-88 $^{8}$

It is still unclear whether BVZ given as part of primary treatment in patients with newly diagnosed GBM in fact influences QOL positively, and further evaluation of the AVAGlio, ${ }^{18}$ RTOG $0825,{ }^{19}$ and the GLARIUS ${ }^{20}$ studies is therefore needed.

\section{Conclusion}

BVZ given as part of primary treatment in newly diagnosed GBM patients is feasible and safe. It does prolong PFS, but not OS. It might influence QOL, but we still await critical evaluation of published data. No molecular or clinical data are available that can predict which subpopulation of patients might benefit from BVZ treatment.

\section{Disclosure}

The authors report no conflicts of interest in this work.

\section{Reference}

1. Stupp R, Mason WP, van den Bent MJ et al. Radiotherapy plus concomitant and adjuvant temozolomide for glioblastoma. $N$ Engl J Med 2005;352(10):987-996.

2. Hicklin DJ, Ellis LM. Role of the vascular endothelial growth factor pathway in tumor growth and angiogenesis. J Clin Oncol 2005;23(5):1011-1027.

3. Plate KH, Scholz A, Dumont DJ. Tumor angiogenesis and antiangiogenic therapy in malignant gliomas revisited. Acta Neuropathol 2012;124(6):763-775.

4. Jain RK. Normalization of tumor vasculature: an emerging concept in antiangiogenic therapy. Science 2005;307(5706):58-62.

5. Batchelor TT, Gerstner ER, Emblem KE et al. Improved tumor oxygenation and survival in glioblastoma patients who show increased blood perfusion after cediranib and chemoradiation. Proc Natl Acad Sci USA 2013;110(47):19059-19064.
6. de Groot JF, Mandel JJ. Update on anti-angiogenic treatment for malignant gliomas. Curr Oncol Rep 2014;16(4):380.

7. Han K, Ren M, Wick W et al. Progression-free survival as a surrogate endpoint for overall survival in glioblastoma: a literature-based metaanalysis from 91 trials. Neuro Oncol 2014;16(5):696-706.

8. Henriksson R, Asklund T, Poulsen HS. Impact of therapy on quality of life, neurocognitive function and their correlates in glioblastoma multiforme: a review. J Neurooncol 2011;104(3):639-646.

9. Jakobsen JN, Hasselbalch B, Stockhausen MT, Lassen U, Poulsen HS. Irinotecan and bevacizumab in recurrent glioblastoma multiforme. Expert Opin Pharmacother 2011;12(5):825-833.

10. Olson JJ, Nayak L, Ormond DR et al. The role of targeted therapies in the management of progressive glioblastoma : A systematic review and evidence-based clinical practice guideline. J Neurooncol 2014.

11. Chauffert B, Feuvret L, Bonnetain F et al. Randomized phase II trial of irinotecan and bevacizumab as neo-adjuvant and adjuvant to temozolomide-based chemoradiation compared to temozolomide-chemoradiation for unresectable glioblastoma. Final results of the TEMAVIR study from ANOCEF. Ann Oncol 2014.

12. Hofland KF, Hansen S, Sorensen M et al. Neoadjuvant bevacizumab and irinotecan versus bevacizumab and temozolomide followed by concomitant chemoradiotherapy in newly diagnosed glioblastoma multiforme: A randomized phase II study. Acta Oncol 2014.

13. Lai A, Tran A, Nghiemphu PL et al. Phase II study of bevacizumab plus temozolomide during and after radiation therapy for patients with newly diagnosed glioblastoma multiforme. J Clin Oncol 2011; 29(2):142-148.

14. Lou E, Peters KB, Sumrall AL et al. Phase II trial of upfront bevacizumab and temozolomide for unresectable or multifocal glioblastoma. Cancer Med 2013;2(2):185-195.

15. Narayana A, Gruber D, Kunnakkat $S$ et al. A clinical trial of bevacizumab, temozolomide, and radiation for newly diagnosed glioblastoma. J Neurosurg 2012;116(2):341-345.

16. Omuro A, Beal K, Gutin P, et al. Phase II study of bevacizumab, temozolomide, and hypofractionated stereotactic radiotherapy for newly diagnosed glioblastoma. Clin Cancer Res. Epub August 8 2014.

17. Vredenburgh JJ, Desjardins A, Reardon DA et al. The addition of bevacizumab to standard radiation therapy and temozolomide followed by bevacizumab, temozolomide, and irinotecan for newly diagnosed glioblastoma. Clin Cancer Res 2011;17(12):4119-4124.

18. Chinot OL, Wick W, Mason W et al. Bevacizumab plus radiotherapytemozolomide for newly diagnosed glioblastoma. $N$ Engl J Med 2014;370(8):709-722.

19. Gilbert MR, Dignam JJ, Armstrong TS et al. A randomized trial of bevacizumab for newly diagnosed glioblastoma. $N$ Engl J Med 2014;370(8):699-708.

20. Herrlinger, U, Schäfer, N, Steinbach, JP et al. Survival and quality of life in the randomized, multicenter GLARIUS trial investigating bevacizumab/irinotecan versus standard temozolomide in newly diagnosed, MGMT-non-methylated glioblastoma patients. J Clin Oncol. May 31, 2014;32(5s):(suppl; abstr 2042).

21. Folkman J. Tumor angiogenesis: therapeutic implications. N Engl J Med 1971;285(21):1182-1186.

22. Sathornsumetee $\mathrm{S}$, Rich JN. Antiangiogenic therapy in malignant glioma: promise and challenge. Curr Pharm Des 2007;13(35):3545-3558.

23. Bergers G, Hanahan D. Modes of resistance to anti-angiogenic therapy. Nat Rev Cancer 2008;8(8):592-603.

24. Lucio-Eterovic AK, Piao Y, de Groot JF. Mediators of glioblastoma resistance and invasion during antivascular endothelial growth factor therapy. Clin Cancer Res 2009;15(14):4589-4599.

25. Piao Y, Liang J, Holmes L et al. Acquired resistance to anti-VEGF therapy in glioblastoma is associated with a mesenchymal transition. Clin Cancer Res 2013;19(16):4392-4403.

26. Jain RK. Normalizing tumor vasculature with anti-angiogenic therapy: a new paradigm for combination therapy. Nat Med 2001;7(9): 987-989. 
27. Chae SS, Kamoun WS, Farrar CT et al. Angiopoietin-2 interferes with anti-VEGFR2-induced vessel normalization and survival benefit in mice bearing gliomas. Clin Cancer Res 2010;16(14):3618-3627.

28. Goel S, Duda DG, Xu L et al. Normalization of the vasculature for treatment of cancer and other diseases. Physiol Rev 2011;91(3):1071-1121.

29. McGee MC, Hamner JB, Williams RF et al. Improved intratumoral oxygenation through vascular normalization increases glioma sensitivity to ionizing radiation. Int J Radiat Oncol Biol Phys 2010;76(5):1537-1545.

30. Winkler F, Kozin SV, Tong RT et al. Kinetics of vascular normalization by VEGFR2 blockade governs brain tumor response to radiation: role of oxygenation, angiopoietin-1, and matrix metalloproteinases. Cancer Cell 2004;6(6):553-563.

31. Hamerlik P, Lathia JD, Rasmussen R et al. Autocrine VEGF-VEGFR2Neuropilin-1 signaling promotes glioma stem-like cell viability and tumor growth. J Exp Med 2012;209(3):507-520.

32. Friedman HS, Prados MD, Wen PY et al. Bevacizumab alone and in combination with irinotecan in recurrent glioblastoma. J Clin Oncol 2009;27(28):4733-4740.

33. Michaelsen SR, Christensen IJ, Grunnet K et al. Clinical variables serve as prognostic factors in a model for survival from glioblastoma multiforme: an observational study of a cohort of consecutive non-selected patients from a single institution. BMC Cancer 2013;13:402.

34. Hegi ME, Diserens AC, Gorlia T et al. MGMT gene silencing and benefit from temozolomide in glioblastoma. $N$ Engl J Med 2005; 352(10):997-1003.

35. Gilbert MR, Wang M, Aldape KD et al. Dose-dense temozolomide for newly diagnosed glioblastoma: a randomized phase III clinical trial. $J$ Clin Oncol 2013;31(32):4085-4091.

36. Bloch O, Safaee M, Sun MZ et al. Disseminated progression of glioblastoma after treatment with bevacizumab. Clin Neurol Neurosurg 2013;115(9):1795-1801.

37. Chamberlain MC. Radiographic patterns of relapse in glioblastoma. J Neurooncol 2011;101(2):319-323.

38. Pope WB, Xia Q, Paton VE et al. Patterns of progression in patients with recurrent glioblastoma treated with bevacizumab. Neurology 2011;76(5):432-437.

39. de Groot JF, Fuller G, Kumar AJ et al. Tumor invasion after treatment of glioblastoma with bevacizumab: radiographic and pathologic correlation in humans and mice. Neuro Oncol 2010;12(3):233-242.

40. Keunen O, Johansson M, Oudin A et al. Anti-VEGF treatment reduces blood supply and increases tumor cell invasion in glioblastoma. Proc Natl Acad Sci USA 2011;108(9):3749-3754.

41. Hasselbalch B, Eriksen JG, Broholm H et al. Prospective evaluation of angiogenic, hypoxic and EGFR-related biomarkers in recurrent glioblastoma multiforme treated with cetuximab, bevacizumab and irinotecan. APMIS 2010;118(8):585-594.

42. Laffaire J, Di Stefano AL, Chinot $O$ et al. An ANOCEF genomic and transcriptomic microarray study of the response to irinotecan and bevacizumab in recurrent glioblastomas. Biomed Res Int 2014 2014:282815.

43. Sathornsumetee S, Cao Y, Marcello JE et al. Tumor angiogenic and hypoxic profiles predict radiographic response and survival in malignant astrocytoma patients treated with bevacizumab and irinotecan. J Clin Oncol 2008;26(2):271-278.

44. DeLay M, Jahangiri A, Carbonell WS et al. Microarray analysis verifies two distinct phenotypes of glioblastomas resistant to antiangiogenic therapy. Clin Cancer Res 2012;18(10):2930-2942.

45. Paez-Ribes M, Allen E, Hudock J et al. Antiangiogenic therapy elicits malignant progression of tumors to increased local invasion and distant metastasis. Cancer Cell 2009;15(3):220-231.

46. Jubb AM, Browning L, Campo L et al. Expression of vascular Notch ligands Delta-like 4 and Jagged-1 in glioblastoma. Histopathology 2012;60(5):740-747.

47. Lu-Emerson C, Snuderl M, Kirkpatrick ND et al. Increase in tumorassociated macrophages after antiangiogenic therapy is associated with poor survival among patients with recurrent glioblastoma. Neuro Oncol 2013;15(8):1079-1087.
48. Murdoch C, Muthana M, Coffelt SB, Lewis CE. The role of myeloid cells in the promotion of tumour angiogenesis. Nat Rev Cancer 2008;8(8):618-631.

49. Lu KV, Bergers G. Mechanisms of evasive resistance to anti-VEGF therapy in glioblastoma. CNS Oncol 2013;2(1):49-65.

50. Piao Y, Liang J, Holmes L et al. Glioblastoma resistance to antiVEGF therapy is associated with myeloid cell infiltration, stem cell accumulation, and a mesenchymal phenotype. Neuro Oncol 2012;14(11):1379-1392.

51. Shojaei F, Wu X, Zhong C et al. Bv8 regulates myeloid-cell-dependent tumour angiogenesis. Nature 2007;450(7171):825-831.

52. Janbazian L, Karamchandani J, Das S. Mouse models of glioblastoma: lessons learned and questions to be answered. J Neurooncol 2014; 118(1):1-8.

53. Jahangiri A, De LM, Miller LM et al. Gene expression profile identifies tyrosine kinase c-Met as a targetable mediator of antiangiogenic therapy resistance. Clin Cancer Res 2013;19(7):1773-1783.

54. Lu KV, Chang JP, Parachoniak CA et al. VEGF inhibits tumor cell invasion and mesenchymal transition through a MET/VEGFR2 complex. Cancer Cell 2012;22(1):21-35.

55. Francescone R, Scully S, Bentley B et al. Glioblastoma-derived tumor cells induce vasculogenic mimicry through Flk-1 protein activation. J Biol Chem 2012;287(29):24821-24831.

56. Yao X, Ping Y, Liu Y et al. Vascular endothelial growth factor receptor 2 (VEGFR-2) plays a key role in vasculogenic mimicry formation, neovascularization and tumor initiation by Glioma stem-like cells. PLoS One 2013;8(3):e57188.

57. Lampson LA. Monoclonal antibodies in neuro-oncology: Getting past the blood-brain barrier. MAbs 2011;3(2):153-160.

58. Phillips, H, Sandman, T, Li, C et al. Correlation of molecular subtypes with survival in AVAglio (bevacizumab [Bv] and radiotherapy [RT] and temozolomide [T] for newly diagnosed glioblastoma [GB]). J Clin Oncol. 2014;32(5):(suppl; abstr 2001).

59. Phillips HS, Kharbanda S, Chen R et al. Molecular subclasses of highgrade glioma predict prognosis, delineate a pattern of disease progression, and resemble stages in neurogenesis. Cancer Cell 2006;9(3):157-173.

60. Verhaak RG, Hoadley KA, Purdom E et al. Integrated genomic analysis identifies clinically relevant subtypes of glioblastoma characterized by abnormalities in PDGFRA, IDH1, EGFR, and NF1. Cancer Cell 2010;17(1):98-110.

61. Wong ET, Gautam S, Malchow C et al. Bevacizumab for recurrent glioblastoma multiforme: a meta-analysis. J Natl Compr Canc Netw 2011;9(4):403-407.

62. Anderson MD, Hamza MA, Hess KR, Puduvalli VK. Implications of bevacizumab discontinuation in adults with recurrent glioblastoma. Neuro Oncol 2014;16(6):823-828.

63. Armstrong TS, Wen PY, Gilbert MR, Schiff D. Management of treatment-associated toxicites of anti-angiogenic therapy in patients with brain tumors. Neuro Oncol 2012;14(10):1203-1214.

64. Macdonald DR, Cascino TL, Schold SC, Jr., Cairncross JG. Response criteria for phase II studies of supratentorial malignant glioma. J Clin Oncol 1990;8(7):1277-1280.

65. Reardon DA, Galanis E, DeGroot JF et al. Clinical trial end points for high-grade glioma: the evolving landscape. Neuro Oncol 2011; 13(3):353-361.

66. Wen PY, Macdonald DR, Reardon DA et al. Updated response assessment criteria for high-grade gliomas: response assessment in neurooncology working group. J Clin Oncol 2010;28(11):1963-1972.

67. Finn MA, Blumenthal DT, Salzman KL, Jensen RL. Transient postictal MRI changes in patients with brain tumors may mimic disease progression. Surg Neurol 2007;67(3):246-250.

68. Henegar MM, Moran CJ, Silbergeld DL. Early postoperative magnetic resonance imaging following nonneoplastic cortical resection. $J \mathrm{Neu}$ rosurg 1996;84(2):174-179.

69. Kumar AJ, Leeds NE, Fuller GN et al. Malignant gliomas: MR imaging spectrum of radiation therapy- and chemotherapy-induced necrosis of the brain after treatment. Radiology 2000;217(2):377-384. 
70. Ulmer S, Braga TA, Barker FG et al. Clinical and radiographic features of peritumoral infarction following resection of glioblastoma. Neurology 2006;67(9):1668-1670.

71. Brandsma D, Stalpers L, Taal W, Sminia P, van den Bent MJ. Clinical features, mechanisms, and management of pseudoprogression in malignant gliomas. Lancet Oncol 2008;9(5):453-461.

72. Chamberlain MC, Glantz MJ, Chalmers L, Van HA, Sloan AE. Early necrosis following concurrent Temodar and radiotherapy in patients with glioblastoma. $J$ Neurooncol 2007;82(1):81-83.

73. de Wit MC, de Bruin HG, Eijkenboom W, Sillevis Smitt PA, van den Bent MJ. Immediate post-radiotherapy changes in malignant glioma can mimic tumor progression. Neurology 2004;63(3):535-537.

74. Taal W, Brandsma D, de Bruin HG et al. Incidence of early pseudoprogression in a cohort of malignant glioma patients treated with chemoirradiation with temozolomide. Cancer 2008;113(2):405-410.

75. Henson JW, Ulmer S, Harris GJ. Brain tumor imaging in clinical trials. AJNR Am J Neuroradiol 2008;29(3):419-424.

76. Sorensen AG, Batchelor TT, Wen PY, Zhang WT, Jain RK. Response criteria for glioma. Nat Clin Pract Oncol 2008;5(11):634-644.

77. van den Bent MJ, Vogelbaum MA, Wen PY, Macdonald DR, Chang SM. End point assessment in gliomas: novel treatments limit usefulness of classical Macdonald's Criteria. J Clin Oncol 2009;27(18):2905-2908.

78. Vredenburgh JJ, Desjardins A, Herndon JE et al. Bevacizumab plus irinotecan in recurrent glioblastoma multiforme. J Clin Oncol 2007;25(30):4722-4729.

79. Hygino da Cruz LC Jr, Rodriguez I, Domingues RC, Gasparetto EL, Sorensen AG. Pseudoprogression and pseudoresponse: imaging challenges in the assessment of posttreatment glioma. AJNR Am J Neuroradiol 2011;32(11):1978-1985.

80. Chinot OL, Macdonald DR, Abrey LE et al. Response assessment criteria for glioblastoma: practical adaptation and implementation in clinical trials of antiangiogenic therapy. Curr Neurol Neurosci Rep 2013;13(5):347.

81. Gallego Perez-Larraya J, Lahutte M, Petrirena G et al. Response assessment in recurrent glioblastoma treated with irinotecan-bevacizumab: comparative analysis of the Macdonald, RECIST, RANO, and RECIST + F criteria. Neuro Oncol 2012;14(5):667-673.

82. Colavolpe $\mathrm{C}$, Chinot $\mathrm{O}$, Metellus $\mathrm{P}$ et al. FDG-PET predicts survival in recurrent high-grade gliomas treated with bevacizumab and irinotecan. Neuro Oncol 2012;14(5):649-657.

83. Olivero WC, Dulebohn SC, Lister JR. The use of PET in evaluating patients with primary brain tumours: is it useful? J Neurol Neurosurg Psychiatry 1995;58(2):250-252.

84. Corroyer-Dulmont A, Peres EA, Petit E et al. Detection of glioblastoma response to temozolomide combined with bevacizumab based on muMRI and muPET imaging reveals [18F]-fluoro-L-thymidine as an early and robust predictive marker for treatment efficacy. Neuro Oncol 2013;15(1):41-56

85. Nedergaard MK, Kristoffersen K, Michaelsen SR et al. The Use of Longitudinal 18F-FET MicroPET Imaging to Evaluate Response to Irinotecan in Orthotopic Human Glioblastoma Multiforme Xenografts. PLoS One 2014;9(2):e100009.

86. Galldiks N, Rapp M, Stoffels G et al. Response assessment of bevacizumab in patients with recurrent malignant glioma using [18F] Fluoroethyl-L-tyrosine PET in comparison to MRI. Eur J Nucl Med Mol Imaging 2013;40(1):22-33.

87. Brandes AA, Franceschi E, Gorlia T et al. Appropriate end-points for right results in the age of antiangiogenic agents: future options for phase II trials in patients with recurrent glioblastoma. Eur J Cancer 2012;48(6):896-903.

88. Norden AD, Drappatz J, Muzikansky A et al. An exploratory survival analysis of anti-angiogenic therapy for recurrent malignant glioma. J Neurooncol 2009;92(2):149-155.

89. Taphoorn MJ, Klein M. Evaluation of cognitive functions and quality of life. Handb Clin Neurol 2012;104:173-183.
90. Bosma I, Vos MJ, Heimans JJ et al. The course of neurocognitive functioning in high-grade glioma patients. Neuro Oncol 2007; 9(1):53-62.

91. Meyers CA, Scheibel RS. Early detection and diagnosis of neurobehavioral disorders associated with cancer and its treatment. Oncology (Williston Park) 1990;4(7):115-122.

92. de Vries MA, van Litsenburg RR, Huisman J et al. Effect of dexamethasone on quality of life in children with acute lymphoblastic leukaemia: a prospective observational study. Health Qual Life Outcomes 2008;6:103.

93. Lupien SJ, Gillin CJ, Hauger RL. Working memory is more sensitive than declarative memory to the acute effects of corticosteroids: a doseresponse study in humans. Behav Neurosci 1999;113(3):420-430.

94. Young AH, Sahakian BJ, Robbins TW, Cowen PJ. The effects of chronic administration of hydrocortisone on cognitive function in normal male volunteers. Psychopharmacology (Berl) 1999;145(3):260-266.

95. Hempen C, Weiss E, Hess CF. Dexamethasone treatment in patients with brain metastases and primary brain tumors: do the benefits outweigh the side-effects? Support Care Cancer 2002;10(4):322-328.

96. Sturdza A, Millar BA, Bana N et al. The use and toxicity of steroids in the management of patients with brain metastases. Support Care Cancer 2008;16(9):1041-1048.

97. Bokstein F, Shpigel S, Blumenthal DT. Treatment with bevacizumab and irinotecan for recurrent high-grade glial tumors. Cancer 2008;112(10):2267-2273.

98. Desjardins A, Reardon DA, Herndon JE et al. Bevacizumab plus irinotecan in recurrent WHO grade 3 malignant gliomas. Clin Cancer Res 2008;14(21):7068-7073.

99. Guiu S, Taillibert S, Chinot $\mathrm{O}$ et al. [Bevacizumab/irinotecan. An active treatment for recurrent high grade gliomas: preliminary results of an ANOCEF Multicenter Study]. Rev Neurol (Paris) 2008;164(6-7):588-594.

100. Nghiemphu PL, Liu W, Lee Y et al. Bevacizumab and chemotherapy for recurrent glioblastoma: a single-institution experience. Neurology 2009;72(14):1217-1222.

101. Norden AD, Young GS, Setayesh K et al. Bevacizumab for recurrent malignant gliomas: efficacy, toxicity, and patterns of recurrence. Neurology 2008;70(10):779-787.

102. Burger PC, Dubois PJ, Schold SC, Jr. et al. Computerized tomographic and pathologic studies of the untreated, quiescent, and recurrent glioblastoma multiforme. J Neurosurg 1983;58(2):159-169.

103. Chang EL, Akyurek S, Avalos T et al. Evaluation of peritumoral edema in the delineation of radiotherapy clinical target volumes for glioblastoma. Int J Radiat Oncol Biol Phys 2007;68(1):144-150.

104. Hochberg FH, Pruitt A. Assumptions in the radiotherapy of glioblastoma. Neurology 1980;30(9):907-911.

105. Levin VA, Crafts DC, Norman DM et al. Criteria for evaluating patients undergoing chemotherapy for malignant brain tumors. J Neurosurg 1977;47(3):329-335.

106. Iwamoto FM, Abrey LE, Beal K et al. Patterns of relapse and prognosis after bevacizumab failure in recurrent glioblastoma. Neurology 2009;73(15):1200-1206.

107. Narayana A, Kelly P, Golfinos J et al. Antiangiogenic therapy using bevacizumab in recurrent high-grade glioma: impact on local control and patient survival. $J$ Neurosurg 2009;110(1):173-180.

108. Wick A, Dorner N, Schafer N et al. Bevacizumab does not increase the risk of remote relapse in malignant glioma. Ann Neurol 2011;69(3):586-592.

109. Soffietti R, Trevisan E, Bertero L et al. Bevacizumab and fotemustine for recurrent glioblastoma: a phase II study of AINO (Italian Association of Neuro-Oncology). J Neurooncol 2014; 116(3):533-541.

110. Desjardins A, Reardon DA, Coan A et al. Bevacizumab and daily temozolomide for recurrent glioblastoma. Cancer 2012;118(5): 1302-1312. 


\section{Publish your work in this journal}

Cancer Management and Research is an international, peer-reviewed open access journal focusing on cancer research and the optimal use of preventative and integrated treatment interventions to achieve improved outcomes, enhanced survival and quality of life for the cancer patient The journal welcomes original research, clinical \& epidemiological studies, reviews \& evaluations, guidelines, expert opinion \& commentary, case reports \& extended reports. The manuscript management system is completely online and includes a very quick and fair peerreview system, which is all easy to use. Visit http://www.dovepress.com/ testimonials.php to read real quotes from published authors.

Submit your manuscript here: http://www.dovepress.com/cancer-management-and-research-journal 